\title{
TCF21 genetic polymorphisms and breast cancer risk in Chinese women
}

\author{
Xueren Gao ${ }^{1,2}$, Jiaojiao Yang ${ }^{1,2}$, Mingxi Wang ${ }^{3}$ and Jianqiong Zhang ${ }^{1,2}$ \\ ${ }^{1}$ Key Laboratory of Developmental Genes and Human Disease, Ministry of Education, Department of Microbiology and \\ Immunology, Medical School of Southeast University, Nanjing, Jiangsu, China \\ 2 Jiangsu Key Laboratory of Molecule Imaging and Functional Imaging, Medical School of Southeast University, Nanjing, \\ Jiangsu, China \\ ${ }^{3}$ Department of Medical Oncology, The First Affiliated Hospital of Bengbu Medical College, Bengbu, Anhui, China \\ Correspondence to: Jianqiong Zhang, email: zhjq@seu.edu.cn
}

Keywords: polymorphism, breast cancer, risk

Received: March 07, $2016 \quad$ Accepted: May 20, 2016

Published: June 05, 2016

\section{ABSTRACT}

Transcription factor 21 (TCF21) functions as a tumor suppressor and is inactivated in several types of cancer. The purpose of this study is to investigate whether TCF21 genetic polymorphisms (rs2327429 T>C, rs2327430 T>C, rs2327433 A>G, rs12190287 C>G, rs7766238 G>A, rs4896011 T>A) are associated with the risk of breast cancer in Chinese women. Logistic regression analyses showed that TCF21 rs12190287 polymorphism was significantly associated with the reduced risk of breast cancer. Stratified analyses based on pathological type indicated that TCF21 rs12190287 polymorphism was only associated with the reduced risk of infiltrative ductal carcinoma. Real-time quantitative PCR analyses revealed that compared with those carrying rs12190287 CC genotype, subjects with GG genotype had higher expression levels of TCF21 mRNA in normal breast tissues. Furthermore, luciferase activity assay showed that the rs12190287 $\mathrm{G}$ allele weakened the binding affinity of hsa-miR-224 to TCF21 3' UTR. These findings suggest that TCF21 rs12190287 polymorphism can regulate TCF 21 expression and may serve as a potential marker for genetic susceptibility to breast cancer.

\section{INTRODUCTION}

Breast cancer is one of the most frequently diagnosed cancers and the principal cause of cancer deaths among women. It is estimated that more than one million women are diagnosed with breast cancer every year, and more than 410,000 will die of the disease [1]. China accounted for $12.2 \%$ of all newly diagnosed breast cancers and $9.6 \%$ of all breast cancer-related deaths worldwide [2]. Furthermore, the incidence of breast cancer in China has been steadily increasing for decades, and is expected to increase to more than 100 cases per $10^{5}$ women aged 55-69 years by 2021 [2-3]. Over the past few decades, a large number of studies have found that environmental factors and genetic background, such as menstrual and reproductive factors, physical activity, alcohol intake and genetic variations, play an important role in the occurrence of breast cancer, but the etiology of breast cancer is extremely complex and has not been fully elucidated [4,
5]. Thus, more studies are needed to identify novel risk factors for breast cancer, which will contribute to risk prediction and prevention of the disease.

Transcription factor 21 (TCF21) is a member of the basic helix-loop-helix (bHLH) transcription factor family that controls development and differentiation of a variety of cell types $[6,7]$. Recently, TCF21 has been identified as a tumor suppressor and inactivated in several types of cancer [8-11]. For instance, TCF21 was reported to be frequently silenced in colorectal cancer (CRC) cells and tissues. Restoration of TCF 21 expression inhibited CRC cell proliferation, promoted apoptosis and suppressed cell invasion and migration [8]. In addition, TCF21 expression was downregulated in most breast cancer tissues, and TCF21 overexpression could inhibit the proliferation of human breast cancer cell line MDA-MB-231 [11]. It is well-known that single nucleotide polymorphisms (SNPs) in cancer-related genes may affect gene expression through different mechanisms depending on their 
Table 1: Association between TCF21 polymorphisms and breast cancer risk.

\begin{tabular}{|c|c|c|c|c|c|}
\hline & Cases, $n(\%)$ & Controls, $n(\%)$ & \begin{tabular}{|l|} 
Comparison \\
\end{tabular} & ${ }^{\mathrm{a}} \mathrm{OR}(95 \% \mathrm{CI})$ & ${ }^{\mathrm{a}} \boldsymbol{P}$ \\
\hline Discovery Set & $n=406$ & $n=592$ & & & \\
\hline rs2327429 & & & C vs. T & $0.83(0.69-0.99)$ & 0.04 \\
\hline TT & $126(31.0)$ & $154(26.0)$ & CC vs. TT & $0.68(0.47-0.99)$ & 0.04 \\
\hline $\mathrm{CT}$ & $204(50.2)$ & $302(51.0)$ & CT vs. TT & $0.83(0.61-1.11)$ & 0.20 \\
\hline $\mathrm{CC}$ & $76(18.7)$ & $136(23.0)$ & $\mathrm{CC}+\mathrm{CT} v s . \mathrm{TT}$ & $0.78(0.59-1.03)$ & 0.08 \\
\hline$P_{\mathrm{HWF}}$ & & 0.61 & $\mathrm{CC} v s . \mathrm{CT}+\mathrm{TT}$ & $0.77(0.56-1.06)$ & 0.11 \\
\hline rs2327430 & & & C vs. T & $0.94(0.68-1.30)$ & 0.72 \\
\hline TT & $341(84.0)$ & $494(83.4)$ & CC vs. TT & $0.58(0.11-3.00)$ & 0.51 \\
\hline $\mathrm{CT}$ & $63(15.5)$ & $93(15.7)$ & CT vs. TT & $0.98(0.69-1.39)$ & 0.92 \\
\hline $\mathrm{CC}$ & $2(0.5)$ & $5(0.8)$ & $\mathrm{CC}+\mathrm{CT} v s . \mathrm{TT}$ & $0.96(0.68-1.35)$ & 0.82 \\
\hline$P_{\text {HWF }}$ & & 0.79 & $\mathrm{CC} v s . \mathrm{CT}+\mathrm{TT}$ & $0.58(0.11-3.01)$ & 0.51 \\
\hline rs2327433 & & & G vs. A & $0.95(0.74-1.21)$ & 0.66 \\
\hline AA & $287(70.7)$ & $415(70.1)$ & GG vs. AA & $0.68(0.29-1.60)$ & 0.37 \\
\hline $\mathrm{AG}$ & $111(27.3)$ & $160(27.0)$ & GA vs. AA & $0.99(0.75-1.32)$ & 0.97 \\
\hline GG & $8(2.0)$ & $17(2.9)$ & GG + GA vs. AA & $0.97(0.74-1.28)$ & 0.84 \\
\hline$P_{\mathrm{HWF}}$ & & 0.74 & GG $v_{s} . \mathrm{GA}+\mathrm{AA}$ & $0.68(0.29-1.59)$ & 0.37 \\
\hline rs12190287 & & & G vs. C & $0.78(0.65-0.94)$ & 0.01 \\
\hline $\mathrm{CC}$ & $163(40.1)$ & $198(33.4)$ & GG vs. CC & $0.61(0.41-0.90)$ & 0.01 \\
\hline CG & $190(46.8)$ & $288(48.6)$ & CG vs. CC & $0.80(0.61-1.06)$ & 0.12 \\
\hline GG & $53(13.1)$ & $106(17.9)$ & $\mathrm{GG}+\mathrm{CG} v s . \mathrm{CC}$ & $0.75(0.58-0.97)$ & 0.03 \\
\hline$P_{\mathrm{HWF}}$ & & 0.94 & GG vs. CG + CC & $0.69(0.48-0.98)$ & 0.04 \\
\hline rs7766238 & & & A vs. G & $0.91(0.67-1.23)$ & 0.53 \\
\hline GG & $336(82.8)$ & $484(81.8)$ & AA vs. GG & $0.58(0.18-1.85)$ & 0.35 \\
\hline $\mathrm{AG}$ & $66(16.3)$ & $98(16.6)$ & AG vs. GG & $0.97(0.69-1.37)$ & 0.86 \\
\hline AA & $4(1.0)$ & $10(1.7)$ & $\mathrm{AA}+\mathrm{AG} v s . \mathrm{GG}$ & $0.93(0.67-1.30)$ & 0.68 \\
\hline$P_{\mathrm{HWE}}$ & & 0.06 & AA vs. AG + GG & $0.58(0.18-1.86)$ & 0.35 \\
\hline rs4896011 & & & $\mathrm{A} v s . \mathrm{T}$ & $0.84(0.61-1.17)$ & 0.31 \\
\hline TT & $347(85.5)$ & $496(83.8)$ & AA vs. TT & $0.36(0.08-1.69)$ & 0.18 \\
\hline AT & $57(14.0)$ & $88(14.9)$ & AT vs. TT & $0.93(0.65-1.33)$ & 0.68 \\
\hline AA & $2(0.5)$ & $8(1.4)$ & $\mathrm{AA}+\mathrm{AT} v s . \mathrm{TT}$ & $0.88(0.62-1.25)$ & 0.47 \\
\hline$P_{\text {HWF }}$ & & 0.08 & AA $v s . \mathrm{AT}+\mathrm{TT}$ & $0.36(0.08-1.70)$ & 0.18 \\
\hline Validation Set & $n=495$ & $n=633$ & & & \\
\hline rs2327429 & & & C vs. T & $0.94(0.80-1.11)$ & 0.47 \\
\hline TT & $155(31.3)$ & $184(29.1)$ & CC vs. TT & $0.87(0.62-1.22)$ & 0.43 \\
\hline $\mathrm{CT}$ & $237(47.9)$ & $312(49.3)$ & CT vs. TT & $0.89(0.67-1.17)$ & 0.39 \\
\hline $\mathrm{CC}$ & $103(20.8)$ & $137(21.6)$ & $\mathrm{CC}+\mathrm{CT} v s . \mathrm{TT}$ & $0.88(0.68-1.14)$ & 0.34 \\
\hline$P_{\mathrm{HWF}}$ & & 0.83 & $\mathrm{CC} v s . \mathrm{CT}+\mathrm{TT}$ & $0.94(0.71-1.26)$ & 0.69 \\
\hline rs12190287 & & & G vs. C & $0.82(0.69-0.97)$ & 0.02 \\
\hline $\mathrm{CC}$ & $208(42.0)$ & $230(36.3)$ & GG vs. CC & $0.68(0.47-0.97)$ & 0.03 \\
\hline CG & $221(44.6)$ & $295(46.6)$ & $\mathrm{CG} v s . \mathrm{CC}$ & $0.82(0.64-1.06)$ & 0.13 \\
\hline GG & $66(13.3)$ & $108(17.1)$ & $\mathrm{GG}+\mathrm{CG} v s . \mathrm{CC}$ & $0.78(0.62-1.00)$ & 0.05 \\
\hline$P_{\mathrm{HWE}}$ & & 0.42 & GG $v_{s} . \mathrm{CG}+\mathrm{CC}$ & $0.75(0.54-1.05)$ & 0.09 \\
\hline Pooled Analysis & $n=901$ & $n=1225$ & & & \\
\hline rs2327429 & & & C vs. T & $0.89(0.78-1.00)$ & 0.05 \\
\hline TT & $281(31.2)$ & $338(27.6)$ & CC vs. TT & $0.79(0.62-1.01)$ & 0.06 \\
\hline $\mathrm{CT}$ & 441 (48.9) & $614(50.1)$ & CT vs. TT & $0.86(0.71-1.06)$ & 0.16 \\
\hline $\mathrm{CC}$ & $179(19.9)$ & $273(22.3)$ & $\mathrm{CC}+\mathrm{CT}$ vs. TT & $0.84(0.70-1.02)$ & 0.07 \\
\hline$P_{\mathrm{HWF}}$ & & 0.85 & CC vs. CT + TT & $0.87(0.70-1.07)$ & 0.18 \\
\hline rs12190287 & & & G vs. C & $0.80(0.71-0.91)$ & 0.001 \\
\hline
\end{tabular}




\begin{tabular}{|l|l|l|l|l|l|}
\hline CC & $371(41.2)$ & $428(34.9)$ & GG vs. CC & $\mathbf{0 . 6 4}(\mathbf{0 . 4 9 - 0 . 8 4 )}$ & $\mathbf{0 . 0 0 1}$ \\
\hline CG & $411(45.6)$ & $583(47.6)$ & CG vs. CC & $\mathbf{0 . 8 1}(\mathbf{0 . 6 8 - 0 . 9 8})$ & $\mathbf{0 . 0 3}$ \\
\hline GG & $119(13.2)$ & $214(17.5)$ & GG + CG vs. CC & $\mathbf{0 . 7 7}(\mathbf{0 . 6 4 - 0 . 9 2})$ & $\mathbf{0 . 0 0 3}$ \\
\hline$P_{\text {HWF }}$ & & 0.52 & GG vs. CG + CC & $\mathbf{0 . 7 2}(\mathbf{0 . 5 6 - 0 . 9 2 )}$ & $\mathbf{0 . 0 0 7}$ \\
\hline
\end{tabular}

${ }^{a}$ Adjusted for age.

locations. For instance, a functional SNP (rs10719 T > C) in the 3' untranslated region (UTR) of DROSHA gene was associated with the risk of bladder cancer by disturbing the binding of hsa-miR-27b and in turn affecting DROSHA expression [12]. There was also one report that an SNP (rs2295080 G > T) in the promoter region of MTOR gene could affect individual susceptibility to renal cell cancer by modulating the endogenous MTOR expression level [13]. Therefore, we hypothesized that SNPs in TCF21 gene might be associated with breast cancer risk by altering TCF21 expression. To test this hypothesis, we conducted a hospital-based case-control study to evaluate the influence of TCF21 SNPs on the risk of breast cancer in Chinese women. Subsequently, functional assays were performed to explore the mechanism of the polymorphism conferring individual susceptibility to breast cancer.

\section{RESULTS}

\section{Associations between $T C F 21$ polymorphisms and breast cancer risk}

The genotype distributions of TCF21 polymorphisms in cases and controls are shown in Table 1. The observed genotype frequencies of the six polymorphisms in controls conformed to the HardyWeinberg equilibrium (HWE) $\left(P_{\mathrm{HWE}}>0.05\right)$. In the discovery set with 406 cases and 592 controls, genotyping results showed that TCF21 rs2327429 and rs 12190287 polymorphisms were significantly associated with the reduced risk of breast cancer (For rs2327429: C vs. T, $\mathrm{OR}=0.83,95 \% \mathrm{CI}=0.69-0.99, P=0.04 ; \mathrm{CC} v s . \mathrm{TT}, \mathrm{OR}$ $=0.68,95 \% \mathrm{CI}=0.47-0.99, P=0.04$. For $\mathrm{rs} 12190287$ : $\mathrm{G} v s . \mathrm{C}, \mathrm{OR}=0.78,95 \% \mathrm{CI}=0.65-0.94, P=0.01 ; \mathrm{GG}$ vs. $\mathrm{CC}, \mathrm{OR}=0.61,95 \% \mathrm{CI}=0.41-0.90, P=0.01$; GG $+\mathrm{CG}$ vs. CC, $\mathrm{OR}=0.75,95 \% \mathrm{CI}=0.58-0.97, P=0.03$; GG vs. CG $+\mathrm{CC}, \mathrm{OR}=0.69,95 \% \mathrm{CI}=0.48-0.98, P=$ $0.04)$. To confirm the above findings, associations of TCF21 rs2327429 and rs 12190287 polymorphisms with breast cancer risk were further assessed in the validation set containing 495 cases and 633 controls. The results showed that only TCF21 rs12190287 polymorphism was associated with the reduced risk of breast cancer ( $\mathrm{G} v s$. $\mathrm{C}, \mathrm{OR}=0.82,95 \% \mathrm{CI}=0.69-0.97, P=0.02 ; \mathrm{GG} v s . \mathrm{CC}$, $\mathrm{OR}=0.68,95 \% \mathrm{CI}=0.47-0.97, P=0.03)$. Furthermore, similar results were also found in pooled analysis $(\mathrm{G} v s . \mathrm{C}$, $\mathrm{OR}=0.80,95 \% \mathrm{CI}=0.71-0.91, P=0.001 ; \mathrm{GG} v s . \mathrm{CC}, \mathrm{OR}$
$=0.64,95 \% \mathrm{CI}=0.49-0.84, P=0.001 ; \mathrm{CG} v s . \mathrm{CC}, \mathrm{OR}=$ $0.81,95 \% \mathrm{CI}=0.68-0.98, P=0.03 ; \mathrm{GG}+\mathrm{CG} v s . \mathrm{CC}, \mathrm{OR}$ $=0.77,95 \% \mathrm{CI}=0.64-0.92, P=0.003 ; \mathrm{GG} v s . \mathrm{CG}+\mathrm{CC}$, $\mathrm{OR}=0.72,95 \% \mathrm{CI}=0.56-0.92, P=0.007)$.

\section{Stratification analysis of $\quad$ TCF21 $\quad$ rs12190287 polymorphism with breast cancer risk}

The associations of $T C F 21$ rs 12190287 polymorphism with breast cancer risk were further examined with stratification by age, pathological type and tumor stage. As shown in Table 2, stratified analyses based on pathological type indicated that TCF21 rs 12190287 polymorphism was only associated with the reduced risk of infiltrative ductal carcinoma ( $\mathrm{G} v s . \mathrm{C}, \mathrm{OR}=0.78$, $95 \% \mathrm{CI}=0.68-0.89, P<0.001 ; \mathrm{GG}$ vs. $\mathrm{CC}, \mathrm{OR}=0.59$, $95 \% \mathrm{CI}=0.45-0.79, P<0.001 ; \mathrm{CG} v s . \mathrm{CC}, \mathrm{OR}=0.82$, $95 \% \mathrm{CI}=0.67-0.99, P=0.04 ; \mathrm{GG}+\mathrm{CG} v s . \mathrm{CC}, \mathrm{OR}=$ $0.76,95 \% \mathrm{CI}=0.83-0.91, P=0.003 ; \mathrm{GG} v s . \mathrm{CG}+\mathrm{CC}, \mathrm{OR}$ $=0.67,95 \% \mathrm{CI}=0.51-0.86, P=0.002)$.

\section{Effects of rs12190287 genotypes on TCF21 mRNA expression levels}

To assess the effects of rs12190287 genotypes on TCF 21 mRNA expression levels, TCF 21 mRNA expression levels were detected in 39 tumor tissues and adjacent normal tissues with different genotypes. As shown in Figure 1, TCF21 mRNA levels were significantly higher in normal breast tissues with rs 12190287 GG genotypes than in those with rs $12190287 \mathrm{CC}$ genotype $(P$ $<0.05)$.

\section{Bioinformatics analysis of TCF21 rs12190287 polymorphism}

Bioinformatics tools, including TargetScan and miRanda, were used to predict potential function of rs12190287 polymorphism in the 3'UTR region of the TCF21 gene. As shown in Figure S1, rs12190287 polymorphism was located within the seed region (2 to $8 \mathrm{bp}$ from 5' end of miRs) of TCF21 3' UTR and hsa-miR-224 hybridization, and the presence of the rs $12190287 \mathrm{G}$ allele may disrupt the binding of hsamiR-224 and TCF21 3' UTR. 
Table 2: Stratification analysis of TCF21 rs12190287 polymorphism with breast cancer risk.

\begin{tabular}{|c|c|c|c|c|c|c|c|c|c|c|}
\hline \multirow[t]{2}{*}{ Characteristics } & \multirow{2}{*}{$\begin{array}{l}\text { G vs. C } \\
{ }^{\mathrm{a} O R}(95 \% \mathrm{CI})\end{array}$} & \multirow[b]{2}{*}{${ }^{\text {a } P}$} & GG vs. CC & \multirow[b]{2}{*}{ a $P$} & CG vs. CC & \multirow[b]{2}{*}{${ }^{\mathrm{a}} \boldsymbol{P}$} & \multirow{2}{*}{\begin{tabular}{|l|}
$\begin{array}{l}\text { GG + CG vs. } \\
\text { CC }\end{array}$ \\
a OR $(95 \% \mathrm{CI})$
\end{tabular}} & \multirow[b]{2}{*}{${ }^{\text {a } P}$} & \multirow{2}{*}{$\begin{array}{l}\text { GG vs. CG + CC } \\
{ }^{a} \text { OR }(95 \% \mathrm{CI})\end{array}$} & \multirow[b]{2}{*}{${ }^{a} P$} \\
\hline & & & $\begin{array}{|ll|}\text { a OR } & (95 \% \\
\text { CI) } & \\
\end{array}$ & & $\begin{array}{|ll|}\text { aOR } & (95 \% \\
\text { CI }) & \\
\end{array}$ & & & & & \\
\hline \multicolumn{11}{|l|}{ Age (years) } \\
\hline$<50$ & $0.85(0.73-0.99)$ & 0.04 & \begin{tabular}{ll|}
0.74 & $(0.52-$ \\
$1.03)$ & \\
\end{tabular} & 0.07 & $\begin{array}{ll}0.81 & (0.64- \\
1.03) & \\
\end{array}$ & 0.08 & \begin{tabular}{ll|}
0.80 & $(0.64-$ \\
$0.99)$ & \\
\end{tabular} & 0.04 & $0.83(0.61-1.13)$ & 0.23 \\
\hline$\geq 50$ & $0.72(0.58-0.89)$ & 0.002 & \begin{tabular}{ll|}
0.52 & $(0.34-$ \\
$0.80)$ & \\
\end{tabular} & 0.003 & $\begin{array}{ll}0.82 \\
1.13)\end{array}$ & 0.22 & \begin{tabular}{ll|}
0.72 & $(0.54-$ \\
$0.97)$ & \\
\end{tabular} & 0.03 & $0.58(0.39-0.86)$ & 0.01 \\
\hline \multicolumn{11}{|l|}{ Pathological type } \\
\hline $\begin{array}{l}\text { Infiltrative ductal } \\
\text { carcinoma }\end{array}$ & $0.78(0.68-0.89)$ & $<0.001$ & $\begin{array}{|ll|}0.59 & (0.45- \\
0.79) & \\
\end{array}$ & $<0.001$ & $\begin{array}{ll}0.82 & (0.67- \\
0.99) & \\
\end{array}$ & 0.04 & $\begin{array}{|lr|}0.76 & (0.83- \\
0.91) & \\
\end{array}$ & 0.003 & $0.67(0.51-0.86)$ & 0.002 \\
\hline Other carcinoma & $0.93(0.72-1.21)$ & 0.61 & $\begin{array}{|ll|}0.91 & (0.54- \\
1.52) & \\
\end{array}$ & 0.72 & $\begin{array}{ll}0.80 \\
1.20)\end{array}$ & 0.28 & $\begin{array}{|ll|}0.83 & (0.57- \\
1.21) & \\
\end{array}$ & 0.33 & $1.03(0.64-1.64)$ & 0.92 \\
\hline \multicolumn{11}{|l|}{ Stage } \\
\hline $\mathrm{I}+\mathrm{II}$ & $0.80(0.70-0.92)$ & 0.002 & $\begin{array}{|ll|}0.59 & (0.44- \\
0.80) & \\
\end{array}$ & 0.001 & $\begin{array}{|ll|}0.86 & (0.70- \\
1.06) & \\
\end{array}$ & 0.17 & $\begin{array}{|ll|}0.79 & (0.65- \\
0.96) & \\
\end{array}$ & 0.02 & $0.64(0.49-0.85)$ & 0.002 \\
\hline III+IV & $0.79(0.65-0.97)$ & 0.03 & $\begin{array}{|ll|}0.66 & (0.44- \\
0.99) & \\
\end{array}$ & 0.05 & $\begin{array}{ll}0.57 & (0.41- \\
0.79) & \\
\end{array}$ & 0.001 & \begin{tabular}{ll|}
0.60 & $(0.44-$ \\
$0.80)$ & \\
\end{tabular} & 0.001 & $0.88(0.60-1.29)$ & 0.51 \\
\hline
\end{tabular}

${ }^{\text {a }}$ Adjusted for age.

\section{Luciferase activity}

As shown in Figure 2, compared with the pmirGLOTCF21 3' UTR-G, the relative luciferase activity of pmirGLO-TCF21 3' UTR-C was significantly reduced in the presence of hsa-miR-224, suggesting that rs 12190287 polymorphism can regulate TCF 21 mRNA expression by disturbing hsa-miR-224 binding.

\section{DISCUSSION}

MicroRNAs (miRNAs) are a class of evolutionarily conserved, single-stranded, non-coding RNA molecules (18 22 nucleotides), and regulate the expression of roughly $10 \%-30 \%$ of all human genes [14]. Accumulating evidence has linked the dysregulated miRNA expression to cancer [15-17]. For instance, miR-145 was downregulated in non-small cell lung cancer tissues, which was correlated with late clinical stage and poorly differentiated carcinoma [15]. MiR-99b was expressed at high levels in tissues of patients with hepatocellular carcinoma (HCC) and in cell lines derived from HCCs. Elevated levels of miR-99b correlated with poor survival of patients with HCC [16]. In addition, a recent study found that hsa-miR-224 expression was significantly upregulated in breast cancer cell lines, especially in highly invasive MDA-MB-231 cells. HsamiR-224 could inhibit the expression of tumor suppressor gene RKIP by directly targeting its 3' UTR, and contribute to breast cancer cell metastasis [17]. However, there is increasing evidence that genetic variation in miRNA binding site can disrupt miRNA-mediated regulation of gene expression [18, 19]. For instance, FOXO1 rs17592236 C > T polymorphism was associated with reduced risk of HCC. Functional dual luciferase reporter assays verified that the rs17592236 polymorphism was a target site of hsa-miR-137 and modulated the binding affinity of hsa-miR-137 to FOXO1 3' UTR [18]. SCRN1 rs6976789 $\mathrm{C}>\mathrm{T}$ polymorphism located in miR-148a target site, and the rs6976789 variant $\mathrm{T}$ allele enhanced the binding ability of miR-148a [19]. In the current study, we investigated the associations of the TCF21 polymorphisms (rs2327429 T > C, rs2327430 T > C, rs2327433 A > G, rs $12190287 \mathrm{C}>\mathrm{G}, \mathrm{rs} 7766238 \mathrm{G}>\mathrm{A}, \mathrm{rs} 4896011 \mathrm{~T}>\mathrm{A}$ ) with the risk of breast cancer in Chinese women, and found that the TCF21 rs12190287 polymorphism in hsamiR-224 binding site was significantly associated with the reduced risk of breast cancer under all comparison models. Intriguingly, stratified analyses based on pathological type indicated that $T C F 21$ rs12190287 polymorphism was only associated with the reduced risk of infiltrative ductal carcinoma under all comparison models. In addition, in vitro and in vivo studies indicated that rs 12190287 polymorphism had an allele-specific effect on TCF21 mRNA expression. The rs12190287 C allele had a lower transcription activity than $\mathrm{G}$ allele, which supported the hypothesis that functional genetic variants in 3' UTR region could influence miRNA-mediated regulation of gene expression.

To the best of our knowledge, this was the first data on the epidemiology providing comprehensive insights into the effects of TCF21 polymorphisms on the risk of breast cancer. Although some interesting results were found, several limitations should be considered when interpreting our results. For instance, inherent selection bias may exist because the cases and controls were from the hospital. Therefore, the findings of this study should be validated in the future through a population-based study. Furthermore, environmental factors and lifestyle, including ionizing radiation, alcohol consumption and high-fat diets, may interact with TCF21 polymorphisms and were not included in this analysis [20-22]. 


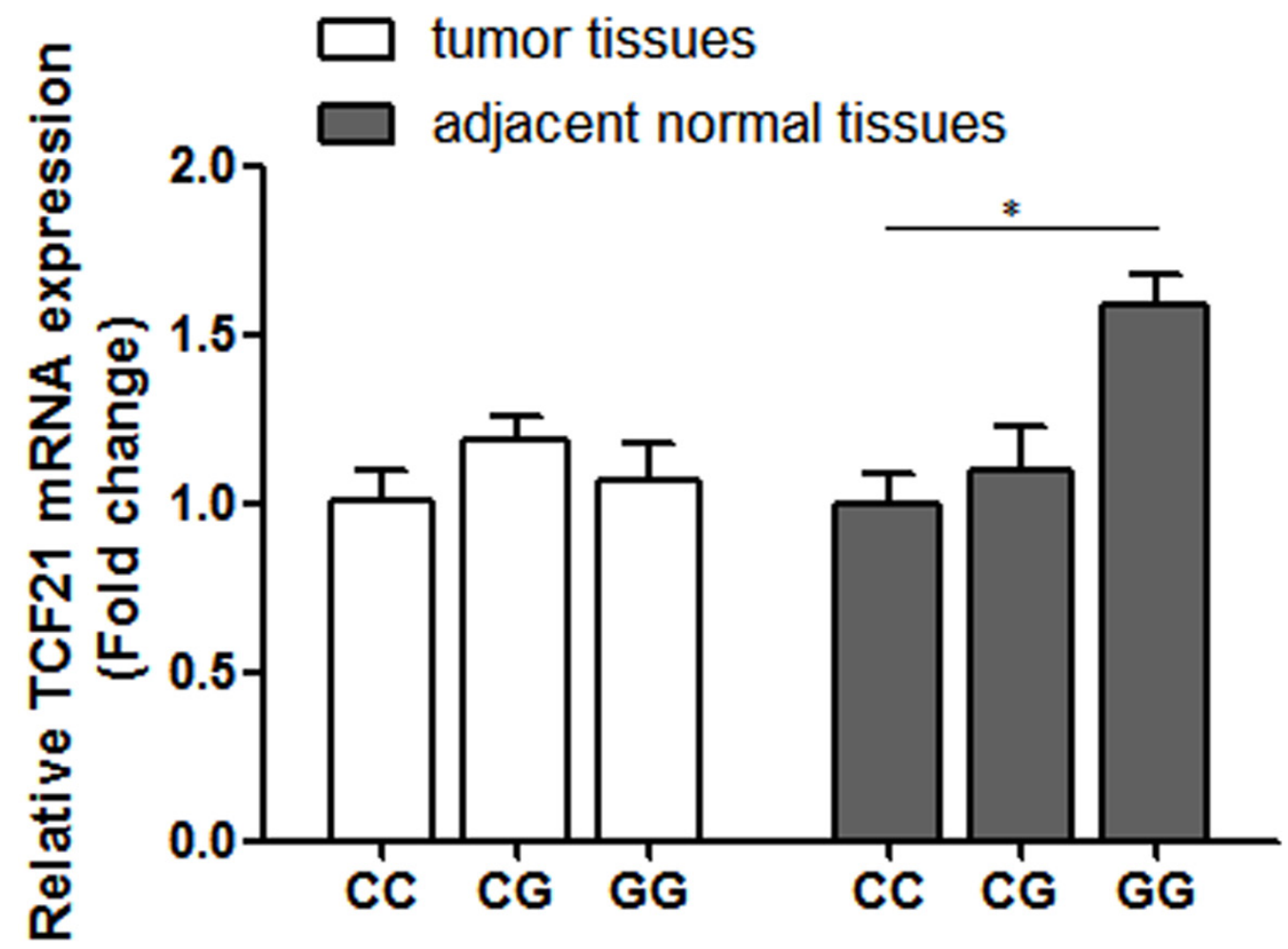

Figure 1: Relative TCF21 mRNA expression in three genotypic groups of rs12190287 (CC, $n=16$; CG, $n=18$; GG, $n$ =5). Data represented as mean $\pm \mathrm{SEM} ; * P<0.05$.

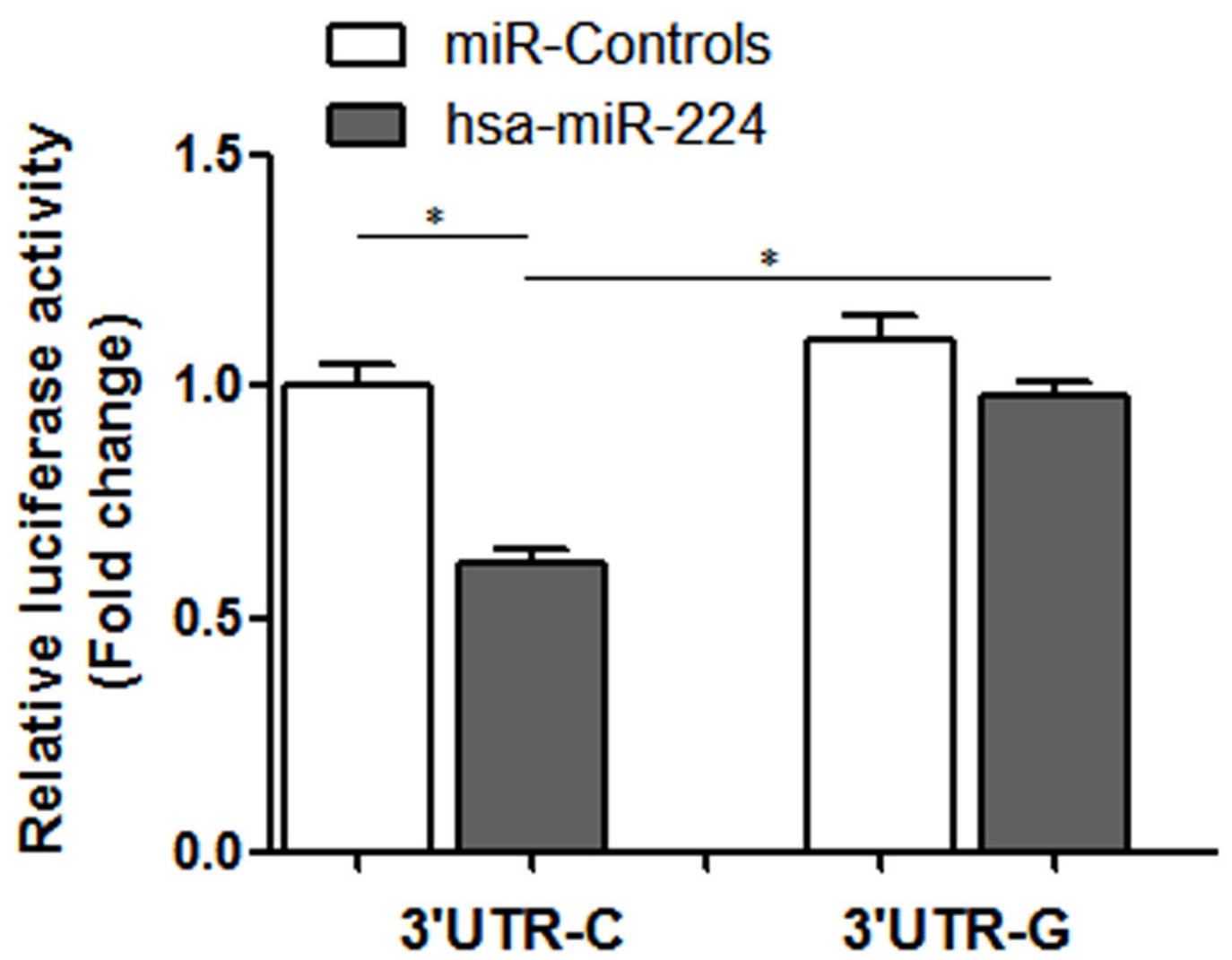

Figure 2: Relative luciferase activity of variant allele on luciferase reporter genes bearing human TCF21 3' UTR in 293T. Data represented as mean $\pm \mathrm{SEM} ; * P<0.01$. 
Taken together, our findings suggest that TCF21 rs12190287 polymorphism can regulate TCF21 expression and may serve as a potential marker for genetic susceptibility to breast cancer in Chinese women.

\section{MATERIALS AND METHODS}

\section{Study subjects}

A total of 901 patients with histopathologically verified breast cancer and 1225 healthy women were consecutively recruited between October 2013 and December 2015 at the Affiliated Hospital of Bengbu Medical College. The selection criteria for all breast cancer patients were that they had no prior history of any cancers and reported no family history of breast cancer. The selection criteria for healthy women who underwent a hospital-based physical examination, were that they had no history of cancer, and were frequency matched to cases on age. In addition, 39 tumor tissues and adjacent normal tissues from the untreated breast cancer patients were collected from the Affiliated Hospital of Bengbu Medical College between October 2013 and March 2014. All subjects were ethnically homogenous Han Chinese from the same geographical region. Clinical information was acquired from medical records and pathology reports (Table S1). Written informed consent was obtained from each subject. The research protocol was approved by the Ethics Committee of the Affiliated Hospital of Bengbu Medical College.

\section{SNPs selection}

Haploview 4.2 and HapMap database of Han Chinese in Beijing (Release 27) was applied to obtain SNPs with a minor allele frequency of more than $5 \%$ in the TCF 21 locus. A total of ten SNPs were obtained in the region of TCF 21 stretching from $2 \mathrm{~kb}$ upstream of the transcriptional start site to the transcriptional stop site (Figure S2). After performing linkage disequilibrium analysis by the Haploview program, we found six tag SNPs that captured all the alleles with a mean $\mathrm{r}^{2}$ of 0.98 (Table S2). Therefore, these SNPs were selected to investigate associations between TCF21 polymorphisms and breast cancer risk.

\section{DNA extraction and genotyping}

Genomic DNA was extracted from peripheral blood lymphocytes of all the studied subjects by a standard salting-out method. Genotypes were determined by the polymerase chain reaction-ligase detection reaction (PCR-LDR) method. The sequences of PCR primers and
LDR probes are summarized in Table S3 and Table S4, respectively. Three LDR probes, including two allele specific probes and one common fluorescent labeled probe, were synthesized for each SNP locus. The LDR parameters were as follows: $94{ }^{\circ} \mathrm{C}$ for $2 \mathrm{~min}, 30$ cycles at $94{ }^{\circ} \mathrm{C}$ for $30 \mathrm{~s}$ and $56{ }^{\circ} \mathrm{C}$ for $3 \mathrm{~min}$. The fluorescent products of LDR were analyzed on ABI 3730xl DNA Analyzer (Applied Biosystems, Foster City, CA, USA). To evaluate the reliability of LDR assays, thirty samples were randomly selected and re-genotyped by DNA sequencing. The results were $100 \%$ concordant.

\section{Real-time quantitative PCR analysis}

Total RNA was isolated from tissue samples using TRIzol reagent following RNase-Free DNase treatment (Invitrogen, Carlsbad, CA, USA). cDNA were synthesized from total RNA using the PrimeScript RT reagent kit with gDNA Eraser (Takara, Otsu, Japan) according to the manufacturer's instructions. The mRNA levels were measured by SYBR green real-time quantitative PCR on a StepOnePlus ${ }^{\text {TM }}$ Real-time PCR System. $\beta$-actin was chosen as the endogenous control to normalize gene expression. Quantitative PCR primer sequences used for TCF21 and $\beta$-actin were shown in Table S5. Relative quantification of TCF21 mRNA was calculated by using the $2^{-\Delta \Delta \mathrm{Ct}}$ method, and each assay was done in triplicate. In all cases, the relative lower TCF21 expression group was used as calibrator (fold change $=1$ ). A melting curve analysis was performed for the PCR products to evaluate primer specificity.

\section{Bioinformatics analysis of TCF21 rs12190287 polymorphism}

TargetScan and miRanda were used to predict potential function of rs 12190287 polymorphism in the 3' UTR region of the TCF21 gene. The human TCF21 3' UTR containing rs 12190287 polymorphism was identified according to the UCSC genome browser (http://genome. ucsc.edu). The mature human miRNA sequences were obtained from the miRBase database (http://www.mirbase. org/).

\section{Dual-luciferase reporter assay}

The human TCF21 3' UTR fragments with rs $12190287 \mathrm{C}$ allele or $\mathrm{G}$ allele were directly synthesized and then respectively inserted into the multiple cloning site of the pmirGLO vector (Promega, Madison, WI, USA) [23]. After cloning, amplification, and DNA sequence confirmation, these vectors were designated as pmirGLO-TCF21 3' UTR-C and pmirGLO-TCF2 1 3' UTR-G, respectively. $293 \mathrm{~T}$ cells were seeded at $1 \times$ 
$10^{5}$ cells per well in 24-well plates. When cells reached $80 \%$ confluence, they were transiently co-transfected with recombinant reporter plasmids and chemically synthesized hsa-miR-224 or negative control miRNA (RiboBio, Guangzhou, China) using Lipofectamin 2000 (Invitrogen, Carlsbad, CA, USA) following manufacturer's instructions. Twenty-four hours after transfection, cells were harvested by the addition of 100 $\mu l$ passive lysis buffer. Luciferase activity was measured by the dual-luciferase reporter assay system (Promega, Madison, WI, USA) and expressed as the ratio of Firefly luciferase to Renilla luciferase activities. In addition, the relative luciferase activity was normalized to 3' UTR-C + miR-Controls, shown as fold change. Three independent transfection experiments were performed, and each luciferase assay was done in triplicate with the same conditions.

\section{Statistical analysis}

All data were analyzed with SPSS version 19.0 (SPSS Inc., Chicago, IL, USA). Differences in the distributions of age between cases and controls were detected using chi-square $\left(\chi^{2}\right)$ test. A goodness-of-fit $\chi^{2}$ test was used to evaluate HWE in controls. Associations of TCF 21 polymorphisms with breast cancer risk were measured by the odds ratio (OR) and its corresponding 95\% confidence interval (CI), and estimated using a logistic regression model. All ORs and 95\% CIs were adjusted for age when it was appropriate. Student's $t$-test was used to compare the difference in luciferase reporter gene expression. One-way ANOVA test were used to analyze the difference of TCF21 mRNA levels among different genotypes. A $P$ value of less than 0.05 was considered statistically significant, and all statistical tests were two-sided.

\section{ACKNOWLEDGMENTS}

This study was supported by grants from the National Natural Science Foundation of China (Grant No. 81371609 and 81272400) and Postgraduate Research and Innovation Project in University of Jiangsu Province (KYZZ_0071).

\section{CONFLICTS OF INTEREST}

The authors declare no competing financial interests.

\section{REFERENCES}

1. Coughlin SS, Ekwueme DU. Breast cancer as a global health concern. Cancer Epidemiol. 2009;33:315-318.

2. Fan L, Strasser-Weippl K, Li JJ, St Louis J, Finkelstein DM, $\mathrm{Yu}$ KD, Chen WQ, Shao ZM, Goss PE. Breast cancer in
China. Lancet Oncol. 2014;15:e279-289.

3. Chen C, Huang YB, Liu XO, Gao Y, Dai HJ, Song FJ, Li WQ, Wang J, Yan Y, Wang PS, Wang YG, Chen KX.Active and passive smoking with breast cancer risk for Chinese females: a systematic review and meta-analysis. Chin J Cancer. 2014;33:306-316.

4. Key TJ, Verkasalo PK,Banks E.Epidemiology of breast cancer. Lancet Oncol. 2001;2:133-140.

5. Iwasaki M, Tsugane S. Risk factors for breast cancer: epidemiological evidence from Japanese studies. Cancer Sci. 2011;102:1607-1614.

6. Tandon P, Miteva YV, Kuchenbrod LM, Cristea IM, Conlon FL. Tcf21 regulates the specification and maturation of proepicardial cells. Development. 2013;140:2409-2421.

7. Quaggin SE, Schwartz L, Cui S, Igarashi P, Deimling J, Post M, Rossant J.The basic-helix-loop-helix protein pod1 is critically important for kidney and lung organogenesis. Development. 1999;126:5771-5783.

8. Dai Y, Duan H, Duan C, Zhou R, He Y, Tu Q, Shen L.Down-regulation of TCF21 by hypermethylation induces cell proliferation, migration and invasion in colorectal cancer. Biochem Biophys Res Commun.2016;469:430-436.

9. Yang Z, Li DM, Xie Q, Dai DQ. Protein expression and promoter methylation of the candidate biomarker TCF21 in gastric cancer. J Cancer Res Clin Oncol. 2015;141:211-220.

10. Zhang H, Guo Y, Shang C, Song Y, Wu B. miR-21 downregulated TCF21 to inhibit KISS1 in renal cancer. Urology. 2012;80:1298-1302.

11. Wang J, Gao X, Wang M, Zhang J. Clinicopathological significance and biological role of TCF21 mRNA in breast cancer. Tumour Biol. 2015;36:8679-8683.

12. Yuan L, Chu H, Wang M, Gu X, Shi D, Ma L, Zhong D, Du M, Li P, Tong N, Fu G, Qin C, et al. Genetic variation in DROSHA 3'UTR regulated by hsa-miR-27b is associated with bladder cancer risk. PLoS One. 2013;8:e81524.

13. Cao Q, Ju X, Li P, Meng X, Shao P, Cai H, Wang M, Zhang Z, Qin C, Yin C.A functional variant in the MTOR promoter modulates its expression and is associated with renal cell cancer risk. PLoS One. 2012;7:e50302.

14. Berezikov E, Guryev V, van de Belt J, Wienholds E, Plasterk RH, Cuppen E. Phylogenetic shadowing and computational identification of human microRNA genes. Cell. 2005;120:21-24.

15. Shen H, Shen J, Wang L, Shi Z, Wang M, Jiang BH, Shu Y.Low miR-145 expression level is associated with poor pathological differentiation and poor prognosis in non-small cell lung cancer. Biomed Pharmacother. 2015;69:301-305.

16. Yang J, Liu X, Yuan X, Wang Z.miR-99b promotes metastasis of hepatocellular carcinoma through inhibition of claudin 11 expression and may serve as a prognostic marker. Oncol Rep. 2015;34:1415-1423.

17. Huang L, Dai T, Lin X, Zhao X, Chen X, Wang C, Li X, Shen H, Wang X.MicroRNA-224 targets RKIP to control cell invasion and expression of metastasis genes in human 
breast cancer cells. Biochem Biophys Res Commun. 2012;425:127-133.

18. Tan C, Liu S, Tan S, Zeng X, Yu H, Li A, Bei C, Qiu X. Polymorphisms in microRNA target sites of forkhead box $\mathrm{O}$ genes are associated with hepatocellular carcinoma. PLoS One. 2015;10:e0119210.

19. Song P, Zhu H, Zhang D, Chu H, Wu D, Kang M, Wang M, Gong W, Zhou J, Zhang Z, Zhao Q.A genetic variant of miR-148a binding site in the SCRN1 3'-UTR is associated with susceptibility and prognosis of gastric cancer. Sci Rep. 2014;4:7080.

20. Feig SA, Hendrick RE. Radiation risk from screening mammography of women aged 40-49 years. J Natl Cancer Inst Monogr. 1997:119-124.

21. Boffetta P, Hashibe M, La Vecchia C, Zatonski W, Rehm J. The burden of cancer attributable to alcohol drinking. Int J Cancer. 2006;14:884-887.

22. Chlebowski RT, Blackburn GL, Thomson CA, Nixon DW, Shapiro A, Hoy MK, Goodman MT, Giuliano AE, Karanja N, McAndrew P, Hudis C, Butler J, et al.Dietary fat reduction and breast cancer outcome: interim efficacy results from the Women's Intervention Nutrition Study. J Natl Cancer Inst. 2006;14:1767-1776.

23. Miller CL, Haas U, Diaz R, Leeper NJ, Kundu RK, Patlolla B, Assimes TL, Kaiser FJ, Perisic L, Hedin U, Maegdefessel L, Schunkert H, Erdmann J, et al. Coronary heart disease-associated variation in TCF21 disrupts a miR224 binding site and miRNA-mediated regulation. PLoS Genet. 2014;10:e1004263. 